\title{
The Prevalence of Cyberbullying and the Views of 5-12 Grade Pupils and Teachers on Cyberbullying Prevention in Lithuanian Schools
}

\author{
Dziuginta Baraldsnes \\ Faculty of Education, Bergen University College, Norway
}

Copyright (C) 2015 by authors, all rights reserved. Authors agree that this article remains permanently open access under the terms of the Creative Commons Attribution License 4.0 International License

\begin{abstract}
This article analyses the views of cyberbullying prevention among 5-12 grade pupils and teachers in Lithuanian schools. It defines the concept of cyberbullying in the context of school pupils, and analyses the theoretical grounds for prevention of this form of bullying. The article also presents the results of the survey (which was conducted in 2009-2010) and reveals the views of 2064 pupils of $5-12$ grade and their 1062 teachers towards the prevention of cyberbullying. Based on the empirical research, it could be concluded that efforts to prevent cyberbullying among 5-12 grade pupils in school must be consistent, and permanent, and involve the whole school community. From the perspective of the pupils, the most effective measures to prevent cyberbullying should be oriented toward psychological conditioning (to strengthen pupil's self-esteem and to outline the consequences for pupils who are involved in cyberbullying).
\end{abstract}

Keywords Face-to-face Bullying, On-line Aggression, Cyberbullying, Cyberbullying among Pupils, Cyberbullying Prevention

\section{Introduction}

Bullying among pupils is acknowledged as a serious problem in school and has been widely investigated by researches in various countries. In recent years, due to development of sophisticated digital tools, bullying among pupils has taken new form: cyberbullying. The core behavior defining this phenomenon is the spreading of hurtful, humiliating texts or images via the Internet or cellphone [25]. Patchin and Hinduja [15] define cyberbullying as the act of doing intentional and recurrent harm to another person using electronic tools. According to Smith and Slonje [23], a variety of terms are used for this phenomenon: of these, "cyberbullying" is the most common term and others such as "electronic bullying" or "digital bullying" are limited to bullying using digital tools. In this article the term "cyberbullying" is used.

Different types of cyberbullying were identified by Smith, Mahdavi, Carvalho, Fisher, Russell, Tippett [22]. These types of cyberbullying include cyberbullying via mobile phones, in the form of calls, text messages and picture/video clips sent to others or uploaded onto a website; and via the Internet, in the form of abusive messages posted online a such as email, chat-room, instant messaging or websites. According to Dupper [6], cyberbullying involves different levels of communication: private (such as chat or text messaging), semi-public (such as posting a harassing message as chat or text messaging), and public (such as creating a website devote to making fun of the person).

There is some disagreement among researches regarding the criteria of cyberbullying: should the criteria for cyberbullying be the same as those for bullying in general, or are some criteria less meaningful in cyberbullying. For example, the criteria related to the repetition of aggressive behavior or intentional acts may not be relevant since it is generally agreed upon that great personal harm can be done by posting a single offensive picture or video on a website. The debate regarding the criteria for cyberbullying is still going on.

Recently, this form of bullying has become more increasingly prolific and has been wildly investigated by researches in various countries, for example Balding [1], Smith, et al [22], Smith and Slonje [23] the UK; Frisen, Berne, Marin [8] Sweden; Brown, Jackson, Cassidy [2], Li [11] Canada; Campbell [3] Australia; Kowalski, Limber, Agatson [10], Patchin and Hinduja [15, 16] USA and others. The results of these investigations regarding cyberbullying, however, vary from country to country. In Patchin and Hinduja [16] study from the 384 respondents under age 18, $11 \%$ identified themselves as cyberbullies, $29 \%$ reported being the victim of online bullying and almost half of the sample, $47 \%$ had witnessed cyberbullying. A study by Raskauskas and Stoltz [18] found that $48.8 \%$ of the teenagers were cybervictims and $21.4 \%$ were cyberbullies. 
Yabarra, Mitchell [27] found that 4 percent of pupils were involved in cyberbullying in USA in 2000 and that this percentage had risen significantly to 9 percent in 2004; it could be concluded that in four years the percentage of pupils involved in cyberbullying had doubled. The comparable studies carried out in Canada [11], Great Britain [14] and from other countries have also revealed that an increasing percentage of pupils are involved in cyberbullying. However, it is difficult to compare findings because the field of cyberbullying among pupils is still a relatively new research area and tools for measuring this phenomenon are not yet standardized. Therefore, the prevalence of cyberbullying among school pupils may vary from 1 percent in Great Britain [1] to 62 percent in Belgium [26].

Based on these findings, it appears that cyberbullying is not only a significant problem in school, but cyberbullying has become a global phenomenon. Scientists, education specialists, psychologists, politicians and other representatives of the legal system understand the extent of the cyberbullying problem in schools and are developing effective political, legal and strategic tools in an effort to reduce cyberbullying [10]. It should be stressed, however, that virtual environments are not entirely negative; they include positive discourses as well. Pupils are searching for safety in the virtual environment and the proper use of digital tools can increase the sense of social responsibility, and encourage responsible, protective and respectful interactions [2].

It is extremely difficult to prevent cyberbullying among school pupils, because this form of bullying occurs in the virtual rather than the school environment [11], [2], [21]. On the other hand, it should be noted that the roots of this phenomenon are hidden in the school environment. This means that pupils who bully others in the virtual environment are very often attending the same school as the victim, and even in the same grade [20]. Brown et al [2] state that, with the help of all electronic devices, pupils can hide themselves and reincarnate into different characters, because in the virtual environment it is possible to avoid direct confrontation with another person. In the other words, research has shown that the Internet and other electronic tools create a favourable environment for specific behavior, allowing people to present themselves as another actor, to adopt the opposite gender, and to change their age and physical appearance. All of the above-mentioned issues serve to indicate the complexity of the cyberbullying phenomenon and highlight the importance of ongoing investigations of cyberbullying among school pupils, and the need to create effective preventive measures - on both the theoretical and the practical levels.

The research problem. Cyberbullying as a phenomenon has been investigated by various researches in different countries, such as, Kowalski et al [10], Patchin, Hinduje [15, 16] USA; Campbell [3] Australia; Li [11] Canada; Smith et al [22] Great Britain; Smith, Slonje [23] Scandinavian countries; Vandebosch, Van Cleemput [26] Belgium. There has not, however, been much research into the cyberbullying phenomenon in Lithuania. In the literature review, only one study of cyberbullying was found; this revealed that between 6 and 18.4 percent of school pupils in Klaipeda county had experienced cyberbullying once or more in the previous two months via text messages, illustrations, telephone calls, emails, chat-room postings or web-sites [17], although these results represent only one county of Lithuania and cannot be generalized to whole of Lithuania.

Eden, Heiman, Olenik-Shemesh [7] survey highlighted the need to encourage the teachers to design and to plan appropriate actions to prevent cyberbullying. Moreover, teachers, who participated in the survey, suggested that urgent attention must be paid to three aspects: policy making, enhancing awareness of a school team and coping strategies for parents. In the literature review of the field of cyberbullying among pupils, it has been revealed some more preventive measures. Cassidy, Jackson and Brown [4] suggest the following measures to reduce cyberbullying among pupils: the development and implementation of the preventative programs, which are oriented toward teaching pupils about cyberbullying; the creation of an anonymous phone-in line where pupils can report cyberbullying; the establishment of a non-tolerance policy regarding cyberbullying among pupils, that outlines the consequences for pupils who are involved in cyberbullying; the creation of a punishment system for pupils who are involved in cyberbullying; the involvement of the police in cases of cyberbullying; the creation of tools to protect pupils against cyberbullying in a forum that brings together pupils, parents and all school personnel; the development of a positive school culture in which pupils develop good relations with other pupils in school; the organization of a multi-faceted creative teaching program for pupils, that maximizes their extracurricular activities; and the development of pupil's positive self-esteem. These measures for reducing cyberbullying among pupils were taken in the survey carried out in Lithuania in order to find out some existing possible differences between teachers' and pupils' views on cyberbullying prevention and compare the results with the results of the survey which was done by Cassidy et al. [4].

The possible solution of this problem requires comprehensive theoretical and empirical analysis, therefore the research problem of the study is formulated as a question: what possible preventative measures teachers and pupils consider as an effective in the prevention of cyberbullying among school pupils.

The aim of the research is to reveal the prevalence of cyberbullying and 5-12 grade school pupils' views and the teachers' views on cyberbullying prevention in Lithuanian schools.

\section{The Theoretical Discourse on the Prevention of Cyberbullying among School Pupils}

There is an ongoing discussion in this field, the aim of 
which is to produce a clear definition of the bullying among school pupils, in which electronic devices, especially mobile phones or the Internet, are used. In some countries (USA, Canada, Great Britain, Norway, Sweden and other countries), the term "cyberbullying" is used [23]. Only one research article published in Lithuania used the term "electronic bullying" [17]. Other terms for the cyberbullying phenomenon are also used in the research literature; for example, "online aggression" (called "internet aggression"), which does not include bullying by using mobile phones; and "digital bullying", which includes only bullying with using digital tools, and excludes other information technology [23].

In general, cyberbullying is defined as a form of aggressive behaviour, in which electronic tools (mobile telephones or the Internet) are used. From the research perspective, cyberbullying could be defined as an aggressive, intentional act carried out by a group or individual, using electronic forms of contact, repeatedly and over the time against a pupil who cannot easily defend him/herself [22], [23]. This definition includes three main criteria of bullying, such as, intention, repetition and power of imbalance. Furthermore, new criteria, such as anonymity and publicity, have been proposed [20]. There is ongoing discussion whether these criteria are applicable to cyberbullying because it is difficult to identify the intention of the act and the power imbalance in cyberbullying. Furthermore, a single act of cyberbullying can lead to many incidents of victimization for many years. Therefore, incorporating of anonymity, which occur when the identity of a person, who bullies, is unknown and publicity, where the large audience is involved, could give more adequate and precise definition of cyberbullying than the previous common definitions [20].

In the literature, it was found other different classification of cyberbullying, for example: covert and overt cyberbullying [24], traditional bullying in a new context, relational cyberbullying and technically sophisticated cyberbullying [19].

It is not easy to define this phenomenon due to various forms of cyberbullying. Kowalski et al [10] lists the variety of cyberbullying forms: bullying by sending e-mails on the Internet, bullying by sending text messages, bullying, which is going on by using a phone, as well as bullying, which is going on in chat rooms, on websites. Later on those forms of cyberbullying have been further elaborated and Nocentini, Calmaestra, Schultze-Krumbholz, Scheithauer, Ortega, Menesini [13] identified four main types of cyberbullying:

- written-verbal behaviours, such as, phone calls, text messages, e-mails, instant messaging, chats, blogs, social networking communities, websites;

- visual behaviours, such as, posting, sending or sharing compromising pictures and videos through mobile phone or internet;

- exclusion - a behavior which purposefully excludes someone from an online group;
- impersonation, which could be explained by stealing and revealing personal information, using another person's name and account.

In contrast to the most commonly analyzed verbal, physical or socio-relational face-to-face bullying forms, cyberbullying is situated in a virtual environment. There is a common understanding that the virtual world is impersonal, that it is not subject to the real-world norms governing morality, freedom of speech and expression of opinions.

There are some gender and age differences related to cyberbullying. For example, Nelson [12] claims that there are more females involved in cyberbullying than males; that they use this form of bullying in order to remain anonymous. The findings regarding the links between cyberbullying and age are somewhat controversial. According Kowalski and Limber [9], there is evidence that cyberbullying peaks around 13-14 years of age and that girls are more likely to be victims of cyberbullying that boys. The results of a study which was done by Patchin and Hinduja [15], did not identify any significant link between the age of pupils and cyberbullying. Ybarra and Mitchell [27] conducted a survey which showed that there were more internet aggressors among pupils in American schools in the age group 15 years and above than in the age group 10 to 14. Slonje and Smith [20] also found that older (14-16 years) pupils experienced cyberbullying more often than younger (11-14 years) pupils.

Cassidy et al [4] identified the main causes of cyberbullying among school pupils. In their view, the most common triggers for cyberbullying in relation to school are a special clothes style, a distinctive physical appearance, a different ethnic background and failure at school (for example, poor academic or sport achievement). It has been reported, that victims of cyberbullying experience a sense of worthlessness and disempowerment [6]. Raskauskas and Stoltz [18] reported that $93 \%$ of cybervictims said cyberbullying affected them negatively: made them feel sad, hopeless or depressed. A study by Patchin and Hinduja [15] reported, that $42.5 \%$ of victims of cyberbullying were frustrated, $40 \%$ felt angry and $27 \%$ felt sad. Moreover, cyberbullying victims were 1.9 times more likely to have attempted suicide than were others [16].

The literature also reveals that cyberbullying is a response to incidents involving pupils at school. As Brown et al [2] found that negative experience, such us humiliation at school, can be subsequently transferred into the virtual space, using the computer or mobile phone at home. The trigger for cyberbullying may be hidden in the school environment, where pupils can experience physical, verbal or socio-relational bullying or other forms of humiliation. This humiliation is subsequently transferred to the virtual space. Since some schools severely restrict the use of mobile phones and access to the Internet during school hours, cyberbullying is more likely to occur outside of the school environment [22], [20], [11].

Efforts to reduce cyberbullying among school pupils are faced with a very complicated situation. One of the factors is 
the anonymity of the pupils who bully others in the virtual space. Thus, cyberbullying is characterized by stealth. In addition, the cyberbullying is often initiated outside school, which makes it more difficult to identify [15]. Due to the freedom of the word that exists in the virtual environment, it is complicated to gain control over the websites in which negative information is spread. Pupils can take advantage of the new opportunities in the virtual environment, in order to achieve both positive and negative goals. It is not difficult to cut and paste threatening, humiliating information about a person and to spread it in the virtual space. According to Diamandurus, Downs, Jenkins [5] cyberbullying has a vast range compared to verbal, physical or social-relations bullying among pupils.

Cyberbullying can occur in any place, at any time of the day. One-third of the participants in Li's [11] study concluded, that adults are powerless to stop cyberbullying among pupils. Pupils who have experienced cyberbullying often feel helpless and scared, and are not willing to raise awareness about cyberbullying in school. Smith, Slonje [23] support Li's [11] conclusion and add that those pupils need help but don't seek it because of fear of more frequent or more harmful attacks by the abusers.

According to Diamandurus et al [5], it is necessary to develop a plan to prevent bullying among pupils, and cyberbullying must be included in this plan. In the process of developing such a plan, it is important to take into consideration the distinctive nature of the use of electronic media, the various forms of bullying among pupils, the harm caused by cyberbullying and the possible consequences of this experience. The educational activity of cyberbullying prevention should be carried out in every school, family and community, as well as throughout the entire society. At a practical level, cyberbullying prevention among pupils must involve the entire school community (administration, teachers, other staff, pupils and parents) [2]. A strict non-tolerance policy should be established to control unacceptable behaviour or bullying in schools. In this policy, cyberbullying must be taken into account and preventative measures must be taken, such as, strict rules regarding the use of mobile phones and the Internet in school [10]; and the discussion of cases of cyberbullying with pupils in class meetings.

Most researches who are investigating the cyberbullying phenomenon - the prevalence, the problem and the resolution - agree about the need for systemic investigation of cyberbullying among school pupils. Questions about cyberbullying should be an inherent part of all investigations on bullying among pupils [21]. Spears et al. [24] encourage involving pupils as researchers in developing the tool for investigation of cyberbullying, for example, pupils could design the questionnaire and could help in data-collecting.

Many researchers agreed that teachers must have all the information available related to both bullying and cyberbullying among school pupils [3], [2], [11], [10], [23]. Parents should also be aware of cyberbullying, its causes and effects; and should be informed about how they should respond and where they can obtain help, if their child has experienced cyberbullying [23]. It has been observed, that teachers and parents have less knowledge than pupils about the latest, advanced electronic devices and their use. The prime users of these electronic devices are the young, growing generation. Moreover, the pupils think that adults are not able to prevent cyberbullying and therefore, they are less likely to tell the parents and teachers about cyberbullying when they experience it [11].

Willard [25] has found that similar methods can prove effective in reducing cyberbullying as are used in preventing bullying in general. It is important to develop the pupils' abilities to maintain friendships; to respect others and their rights; to stand up for their own rights, without prejudging the rights of others; and to employ conflict resolution skills. According Dupper [6], an innovative strategy to specifically combat cyberbullying is making the Internet a place of social connection and compassion rather than a place of aggression. Further, the author presents different blog sites, such as 37 Days, Lifeline Gallery, and AllDayBuffet. Another specific intervention that is important for preventing cyberbullying is collaboration with telecommunication companies, which provide digital-access links.

The survey carried out by Cassidy et al [4] revealed that most pupils chose the following cyberbullying prevention measures: the anonymous phone-in line (19\%); the preventative programs, which are oriented toward teaching pupils about cyberbullying (18\%); the punishment of pupils who participate in cyberbullying (11\%). Furthermore, the authors conclude that pupils want to dialogue about cyberbullying and want to be a part of the solution. Pupils proposed solutions that dealt with immediate redress (anonymous reporting, punitive measures) but they also suggested long-term, relationship-based solutions that addressed the school culture, pupils' self-esteem and modeling by adults.

\subsection{Methods of the Research}

Theoretical analysis and a written survey were conducted which provided quantitative data for analysis. It was applied parallel forms reliability, which means that it was given two different versions of assessment tool to the same group of pupils and results were correlated in order to evaluate the consistency of results of both versions. In order to assure validity of the survey it was presented clearly defined aim and objectives of the survey, checked if the questionnaire matched the aim and objectives, compared this questionnaire with other available assessment tools, for instance Cassidy et al [4].

In order to include a wide range of respondents who could represent the various regions of the country, schools and grades, the respondents were selected using two-stage systemic sampling. The headmasters of the selected schools were contacted and asked for permission to do the survey. 
Parents of the selected pupils under age 14 were informed about the survey as well and ethical principles of voluntary participation and confidentiality were applied. Respondents (both pupils and teachers) were asked to fill out a questionnaire of 12 items, which consisted of three parts: an introduction, a main part and demographic questions. The detailed instructions how to fill out the questionnaire were given in the introduction together with Patchin's and Hinduja's [15] definition of cyberbullying: "Cyberbullying is an act of doing intentional and recurrent harm to another person using electronic tools. One pupil or group of pupils can bully other pupil via mobile phones, in the form of calls, text messages and picture/video clips sent to others or uploaded onto a website; and via the Internet, in the form of abusive messages posted online a such as email, chat-room, instant messaging or websites". The most important questions were the following: How often have you experienced cyberbullying among pupils in school? (for pupils) How often have you faced with cyberbullying among pupils in school? (for teachers) It was used 5-points scale (Never, 1-3 times a month, 1-2 times a week, 3-5 times a week, and everyday), which are used in other surveys on bullying or cyberbullying. Both groups of the respondents needed to mark the measures to reduce cyberbullying among pupils, which they considered as the most effective, suggested by Cassidy et al [4]. There were used only 2-point scale with answers "Yes" and "No" and thus it was a limitation of the study, which did not allowed respondents to "escape" from the direct answer by choosing the answer "I don't know" or to measure intensity of the answers by using, for instance, 5- or 6- points Likkert scales. Despite of the limitations, the present study contributes to existing literature on cyberbullying in important ways: respondents represented a general set of pupils and teachers in
Lithuanian schools; it was used 5-points scale in order to reveal the prevalence of cyberbullying among pupils in school.

The survey was conducted during the academic year of 2009-2010. The data from the survey were analysed using Statistics Package for Social Science (SPSS-version 19) program (crosstabs, the Pearson Chi-Square test and Mann-Withney U nonparametric test).

\subsection{Respondents}

Description of the pupils who participated in the research: The sample consisted of 2064 5-12 grade pupils: 1153 $(55.96 \%)$ were females and $911(44.05 \%)$ were males; they were selected from 287 schools in 10 different counties in Lithuania. Two-stage selection was applied: in the first stage 10 counties in Lithuania were selected by random sampling. In the second stage, a representative number of schools were selected from the total population of secondary schools in selected counties; and two pupils were selected by random sampling from each grade 5 to 12 and were asked to complete a questionnaire. The distribution of the school pupils according the age, the living area and the type of school is presented in Table 1.

As Table 1 indicates, the largest group of respondents was in the age groups 15 and 16 years old $(30.12 \%)$ : the distribution among the other age groups was more or less equal. The respondents were attending gymnasium (39.87\%), basic school (36.53\%) and secondary school (23.60\%). They were from 101 regions in Lithuania; and the majority of the respondents $(40.78 \%)$ were from the small towns and villages, while $38.38 \%$ were from the county centers, and $20.84 \%$ percent were from the largest cities in Lithuania. Pupils in 5-12 grades in the largest cities of Lithuania constituted the smallest group of respondents.

Table 1. The Distribution of the School Pupils According the Age, the Living Area and the Type of School.

\begin{tabular}{llllll}
\hline Age Groups of the School Pupils & Percentage & Living area & Percentage & Type of school & Percentage \\
\hline 10-12 Years Old & 22.07 & City & 20.84 & Basic school & 36.53 \\
$13-14$ Years Old & 24.60 & Town & 40.78 & Secondary school & 23.60 \\
$15-16$ Years Old & 30.12 & Rural Area & 38.38 & Gymnasium & 39.87 \\
$17-19$ Years Old & 23.21 & & & & \\
\hline
\end{tabular}

Table 2. The Distribution of the Teachers According the Age and Teaching Experience.

\begin{tabular}{llll}
\hline Teacher Age & Percentage & Teaching Experience & Percentage \\
\hline Under 30 Years Old & 10.7 & Up to 10 Years & 22.9 \\
$31-40$ Years Old & 25.8 & From 11 to 20 Years & 26.7 \\
$41-50$ Years Old & 34.9 & From 21 to 30 Years & 31.1 \\
$51-60$ Years Old & 22.3 & More than 31 Years & 19.3 \\
Over 60 Years Old & 6.2 & & \\
\hline
\end{tabular}


Description of the teachers who participated in the research: The teachers from the schools selected for the survey, also completed the same written survey. They were asked about the same cyberbullying preventive measures as the pupils who participated in the research. In total, 1062 teachers took part in the survey: $92.7 \%$ of them were females and only $7.3 \%$ - males. The distribution of the teachers according the age and teaching experience is presented in Table 2.

As Table 2 indicates, the distribution according teachers' age in order of significance was as follows: $41-50$ years old $34.9 \%$, 31-40 years old $-25.8 \%$, 51-60 years old $-22.3 \%$, under 30 years old $-10.7 \%$ and over 61 years old $-6.2 \%$. The distribution of respondents of the survey according to the teaching experience was as follows: up to 10 years of teaching experience $22.9 \%$, from 11 to 20 years $-26.7 \%$, from 21 to 30 years $-31.1 \%$ and more than 31 years $-19.3 \%$. Nine of ten respondents had a university education.

\section{Results and Discussion}

The Lithuanian study reveals the views of teachers and pupils with regard to the frequency of cyberbullying among pupils. The teachers who took part in the survey based their view on the probable frequency of cyberbullying among pupils, while the pupils based their view on actual experiences of cyberbullying. The results are shown in Table 3.

As Table 3 indicates, less than 1/3 (30.95\%) of the teachers thought that their pupils had never been involved in cyberbullying using their mobile phone, and a slightly higher percentage (39.94\%) of the teachers thought that their pupils had never been involved in cyberbullying using the Internet. The results of the pupil's survey revealed that more than half of the pupils who took part in the survey had never been involved in cyberbullying using the mobile phone (51.25\%) and an even higher percentage $(57.11 \%)$ had never been involved in cyberbullying using the Internet.

More than half of the teachers questioned thought that cyberbullying among pupils happened 1-3 times a month; $54.75 \%$ of teachers said that it happened using the mobile phone and $50.81 \%$ using the Internet. In total, every tenth teacher $(9.25 \%)$, who took part in the survey, considered cyberbullying among pupils using the Internet as a serious problem that can happen from 1-2 times a week or every day. The percentage of the teachers who regarded cyberbullying among pupils using the mobile phone as a serious problem is even higher (14.3\%).

In contrast, the pupil's responses indicated that cyberbullying was actually more frequent, and that it occurred more often via the mobile phone than via the Internet. Almost a quarter $(24.46 \%)$ had experienced or witnessed cyberbullying via the Internet from 1-2 times a week to every day. An even higher percentage of pupils (29.56\%) had experienced or witnessed cyberbullying, via the mobile phone from 1-2 times a week to every day. It is useful to analyse the rate of pupils who confirmed that they experienced or witnessed cyberbullying every day. As the results of the survey showed, there are 57 pupils $(2.98 \%)$ who experience or witness cyberbullying daily via the Internet and 67 pupils (3.49\%) who experience or witness cyberbullying daily via mobile phone.

It is evident from these statistics that the views of the teachers and the pupils who took part in the survey differed with regard to the rate of the cyberbullying among pupils. In the teachers' view, this phenomenon involves around $2 / 3$ of pupils and the frequency of exposure to cyberbullying is 1-3 times a month or less. In contrast, the pupils' view indicates a significantly lower rate exposure to cyberbullying, but for those pupils who are exposed to this phenomenon, the frequency was considerably higher, than the teachers had indicated.

Table 3. The Experience of Cyberbullying Among School Pupils: the View of Teachers and Pupils.

\begin{tabular}{lllll}
\hline & \multicolumn{2}{c}{ Teachers' views (\%) } & \multicolumn{2}{c}{ Pupils' views (\%) } \\
\hline \multirow{2}{*}{ Frequency } & $\begin{array}{l}\text { The Experience of } \\
\text { Cyberbullying by Using } \\
\text { the Internet }\end{array}$ & $\begin{array}{l}\text { The Experience of } \\
\text { Cyberbullying by Using the } \\
\text { Mobile Phone }\end{array}$ & $\begin{array}{l}\text { The Experience of } \\
\text { Cyberbullying by Using } \\
\text { the Internet }\end{array}$ & $\begin{array}{l}\text { The Experience of } \\
\text { Cyberbullying by Using the } \\
\text { Mobile Phone }\end{array}$ \\
\hline Never & 39.94 & 30.95 & 57.11 & 51.25 \\
$1-3$ times a month & 50.81 & 54.75 & 18.44 & 19.19 \\
$1-2$ times a week & 6.78 & 10.25 & 17.40 & 19.97 \\
3-5 times a week & 1.29 & 2.56 & 4.08 & 6.10 \\
Everyday & 1.18 & 1.49 & 2.98 & 3.49 \\
\hline
\end{tabular}

Table 4. The Experience of Cyberbullying among School Pupils according the Pupils' Gender by Using the Pearson Chi-Square test.

\begin{tabular}{|c|c|c|c|c|c|c|c|c|c|}
\hline $\begin{array}{c}\text { The } \\
\text { experience of } \\
\text { Cyberbullying }\end{array}$ & Group & Never \% & $\begin{array}{l}1-3 \text { times a } \\
\text { month } \%\end{array}$ & $\begin{array}{c}1-2 \text { times a } \\
\text { week } \%\end{array}$ & $\begin{array}{l}3-5 \text { times a } \\
\text { week } \%\end{array}$ & Everyday \% & $X^{2}$ & $\mathrm{df}$ & $\begin{array}{l}\text { Asymp. Sig. } \\
\text { (2-sided) }\end{array}$ \\
\hline \multirow{2}{*}{$\begin{array}{l}\text { by using the } \\
\text { Internet }\end{array}$} & M & 65.5 & 15.5 & 12.9 & 2.9 & 3.2 & \multirow{2}{*}{47,576} & \multirow{2}{*}{4} & \multirow{2}{*}{,000 } \\
\hline & $\mathrm{F}$ & 50.6 & 20.9 & 20.7 & 5.0 & 2.8 & & & \\
\hline \multirow{2}{*}{$\begin{array}{l}\text { by using the } \\
\text { Mobile Phone }\end{array}$} & M & 59.1 & 16.1 & 16.1 & 4.8 & 3.9 & \multirow{2}{*}{42,031} & \multirow{2}{*}{4} & \multirow{2}{*}{, 000} \\
\hline & $\mathrm{F}$ & 45.0 & 21.7 & 22.9 & 7.2 & 3.2 & & & \\
\hline
\end{tabular}


In the literature there is no clear conclusions regarding gender and cyberbullying among school pupils. Some researchers found no gender differences in cyberbullying [15]. Other studies found that there are some gender differences in cyberbullying, for example, according Vandebosch, Van Cleemput [26], Slonje, Smith [20] boys to be significantly more likely to cyberbully others. The results of Frisen, Berne, Marin [8] survey demonstrate, that there are more girls than boys, who are involved in cyberbullying. In this research, the significant relations between the pupil's gender (in table 4. M - male and $\mathrm{F}$ - female) and age groups (in table 5. 10-14 age group - group 1 and 15-19 age group group 2) and experience of cyberbullying among school pupils have been analyzed by using the Pearson Chi-Square test. The results are shown in Table 4 and Table 5.

As Table 4 indicates more girls than boys have experienced cyberbullying by the Internet or by the usage of mobile phone. For example, there were $65.5 \%$ of boys and $50.6 \%$ of girls who had never experienced cyberbullying via the Internet and $6.1 \%$ of boys and $7.8 \%$ of girls who had experienced cyberbullying via the Internet 3-5 times a week or every day. Moreover, there were $59.1 \%$ of boys and $45.0 \%$ of girls who had never been exposed to cyberbullying by the usage of mobile phone and $8.7 \%$ of boys and $10.4 \%$ of girls who had experienced cyberbullying by the usage of mobile phone 3-5 times a week or every day.

As shown in Table 5, more pupils from the age group 15-19 had experienced cyberbullying via the Internet or by the usage of mobile phone. There were $6.4 \%$ of pupils aged
$10-14$ and $7.8 \%$ of pupils aged $15-19$ who had experienced cyberbullying via the Internet 3-5 times a week or every day. There were $8.7 \%$ of pupils aged $10-14$ and $10.5 \%$ of pupils aged 15-19 who had experienced cyberbullying by the usage of mobile phone 3-5 times a week or every day. Summarizing the experience of cyberbullying among pupils in Lithuanian school, it could be concluded that there is a statistical significance between the experience of cyberbullying among pupils in schools and pupil's gender and age groups. Females and pupils from the age group 15-19 have experience cyberbullying more often than males and pupils from the lower age group.

Turning now to the prevention of cyberbullying, a list of measures, which could help to reduce the cyberbullying among school pupils, was compiled. The measures were taken in accordance with suggested measures by Kowalski et al [10] and Cassidy et al [4]. This list of preventive measures was given to both the teachers and the pupils who participated in the survey and they were asked to state whether or not the measures would be effective in reducing cyberbullying among pupils. The results are presented in Table 6.

It is important first to analyse the results of each group of the respondents in order to determinate the most effective measures to prevent cyberbullying among school pupils; and then to consider the similarities and differences between views of the teacher's and pupil's with regard to these preventative measures.

Table 5. The Significant Relations between the Pupils' Age Groups and the Experience of Cyberbullying among School Pupils by Using Pearson Chi-Square test.

\begin{tabular}{|c|c|c|c|c|c|c|c|c|c|}
\hline $\begin{array}{l}\text { The experience } \\
\text { of } \\
\text { Cyberbullying }\end{array}$ & Group & Never \% & $\begin{array}{l}1-3 \\
\text { times a } \\
\text { month \% }\end{array}$ & $\begin{array}{l}1-2 \text { times a } \\
\text { week } \%\end{array}$ & $\begin{array}{l}3-5 \text { times a } \\
\text { week } \%\end{array}$ & Everyday \% & $\mathrm{X}^{2}$ & $\mathrm{df}$ & $\begin{array}{l}\text { Asymp. } \\
\text { Sig. } \\
\text { (2-sided) }\end{array}$ \\
\hline \multirow{2}{*}{$\begin{array}{l}\text { by using the } \\
\text { Internet }\end{array}$} & 1 & 63.7 & 15.6 & 14.3 & 4.4 & 2.0 & \multirow{2}{*}{36,280} & \multirow{2}{*}{4} & \multirow{2}{*}{0,000} \\
\hline & 2 & 50.1 & 21.3 & 20.2 & 3.9 & 3.9 & & & \\
\hline \multirow{2}{*}{$\begin{array}{l}\text { by using the } \\
\text { Mobile Phone }\end{array}$} & 1 & 58.3 & 16.1 & 16.9 & 5.2 & 3.5 & \multirow{2}{*}{47,576} & \multirow{2}{*}{4} & \multirow{2}{*}{0,000} \\
\hline & 2 & 44.4 & 22.3 & 22.9 & 7.0 & 3.5 & & & \\
\hline
\end{tabular}

Table 6. Measures for Reducing Cyberbullying among School Pupils: Teachers' and Pupils' Views.

\begin{tabular}{|c|c|c|}
\hline Measures for Reducing Cyberbullying among School Pupils. & Teachers' View (\%) & Pupils' View (\%) \\
\hline $\begin{array}{l}\text { Provide Information about Cyberbullying in School and Implement Preventative Programs, } \\
\text { which Teach Pupils about Cyberbullying }\end{array}$ & 56.01 & 42.5 \\
\hline Provide Anonymous Phone-in Line where Pupils Can Report Cyberbullying & 60.72 & 46.45 \\
\hline Develop a Non-tolerance Policy Compliance Regarding Cyberbullying among Pupils & 53.65 & 27.16 \\
\hline Outline the Consequences for Pupils who Are Involved in Cyberbullying & 55.87 & 53.36 \\
\hline Involve the Police in Cyberbullying Cases & 49.68 & 38.63 \\
\hline $\begin{array}{l}\text { Bring Together Pupils, Parents and All School Personnel to Create Tools to Protect Pupils against } \\
\text { Cyberbullying }\end{array}$ & 60.96 & 39.93 \\
\hline $\begin{array}{l}\text { Develop a Positive School Culture in which Pupils Would Develop Cordial Relations with Other } \\
\text { Pupils in School }\end{array}$ & 70.12 & 43.38 \\
\hline $\begin{array}{l}\text { Organize a Multi-faceted Creative Teaching for Pupils, in order to Maximize the Pupils' } \\
\text { Extracurricular Activities }\end{array}$ & 41.35 & 33.06 \\
\hline Strengthen Pupil's Self-esteem & 74.28 & 57.28 \\
\hline Other & 1.05 & 0.00 \\
\hline
\end{tabular}


As shown in Table 6, the teachers favoured more action than the pupils, suggesting various preventative measures against cyberbullying among school pupils. Based on the survey data, it can be concluded that, in teachers' view, the most effective tool for reducing cyberbullying would be strengthening of pupil's self-esteem; nearly three-quarters $(74.28 \%)$ of the teachers thought this would be effective. A slightly lower percentage of the teachers $(70.12 \%)$ felt that, the development of a positive school culture would be effective and slightly less than two-thirds (60.96\%) indicated that working together as a team with pupils, parents, teachers and other school staff to find the best ways to reduce cyberbullying would help. It could be concluded that the majority of the teachers agreed about that, in order to reduce the prevalence of cyberbullying among pupils, it is necessary to work on the psychological factors in school (strengthening of pupil's self-esteem (since pupils with positive self-esteem would not hurt others and would be able to confront the pupils who do so); to work in order to create a safe school environment and reform the school's culture; and finally, to strengthen the cooperation and collaboration between the school community members. From the teacher's perspective, it is very important to provide an opportunity for pupils to report cyberbullying. For instance, almost two-thirds $(60.72 \%)$ favoured the establishment of anonymous phone-in line in school. The other significant measures that teachers favoured included the provision of information about cyberbullying, which could teach pupils about cyberbullying $(56.01 \%)$; the specification of consequences for pupils who are involved in cyberbullying via the Internet or mobile phone $(55.87 \%)$; and the adoption of a non-tolerance policy regarding the cyberbullying among pupils $(53.65 \%)$. Slightly less than half of the teachers $(49.68 \%)$ suggested that it would be good to involve police in cyberbullying cases, and $41.35 \%$ concluded that cyberbullying could be reduced by the organization of a multi-faceted teaching to maximize the pupils' extracurricular activities.

Pupils who completed the written survey agreed with the teachers that the most effective way to prevent cyberbullying would be to strengthen the pupils' self-esteem; more than half part of the school-aged respondents $(57.28 \%)$ considered this measure as very important. The second most important measure for more than half of the pupils $(53.36 \%)$ was the specification of consequences for pupils who are involved in cyberbullying; in other words, the creation of some kind of the punishment system for pupils who bully other pupils using the Internet or mobile phone. Slightly under half of the pupils $(46.45 \%)$ thought that the establishment of an anonymous phone-in line in school was important. These figures reveal that, in the view of the pupils, the most effective preventive measures against cyberbullying focus on the psychological effect of the measure on the pupil involved; for instance, enhancing the pupil's self-esteem or specifying the consequences for pupils engaged in cyberbullying; in other words, to develop a punishment system for perpetrators.

According to Li [11], Willard [25] and other researchers, pupils are unwilling to report cyberbullying, largely because they do not trust the adults' ability to intervene in cyberbullying case and help the pupil who had been exposed to cyberbullying. Therefore, the creation of anonymous phone-in line could encourage pupils to talk more openly about cyberbullying and at the same time to reduce the rate of cyberbullying. More than $40 \%$ of the pupils (43.38\% and $42.5 \%$ respectively) emphasized the importance of a positive, safe school environment. In order to reduce cyberbullying, it is necessary to provide information about this phenomenon and to implement preventative programs that teach pupils about cyberbullying. In pupils' view, less important measures included: bringing together pupils, parents and all school personnel to create tools to protect pupils against cyberbullying (39.93\%); involving the police in cyberbullying cases (38.63\%); and organizing a multi-faceted creative teaching for pupils, in order to maximize the pupils' extracurricular activities (33.06\%).

The statistics analysis using Mann-Withney U nonparametric test indicated five significant relations between gender and one significant relation between pupils' age groups and some measures for reducing cyberbullying. These significant relations are shown in Table 7.

Table 7. The Significant Relations between the Pupils' Gender, Age Groups and Measures for Reducing Cyberbullying among School Pupils by Using Mann-Whitney U Test.

\begin{tabular}{|c|c|c|c|c|}
\hline Measures for Reducing Cyberbullying among School Pupils. & Mann-Whitney U Test & Asymp. Sig. (2-tailed) & Pupils' Groups & Mean Rank \\
\hline \multirow{2}{*}{$\begin{array}{l}\text { Provide Anonymous Phone-in Line where Pupils Can Report } \\
\text { Cyberbullying }\end{array}$} & \multirow{2}{*}{415825,000} & \multirow{2}{*}{,004 } & Male & 917,49 \\
\hline & & & Female & 981,60 \\
\hline Outline the Consequences for Pupils who are Involved in & \multirow{2}{*}{415884,000} & \multirow{2}{*}{,004 } & Male & 917,68 \\
\hline Cyberbullying & & & Female & 980,55 \\
\hline Develop a Positive School Culture in which Pupils Would & \multirow{2}{*}{391005,500} & \multirow{2}{*}{,000 } & Male & 887,26 \\
\hline Develop Cordial Relations with Other Pupils in School & & & Female & 1004,46 \\
\hline \multirow{2}{*}{$\begin{array}{l}\text { Organize a Multi-faceted Creative Teaching for Pupils, in order } \\
\text { to Maximize the Pupils' Extracurricular Activities }\end{array}$} & \multirow{2}{*}{408532,500} & \multirow{2}{*}{,000 } & Male & 908,60 \\
\hline & & & Female & 988,32 \\
\hline \multirow{2}{*}{ Strengthen Pupil's Self-esteem } & \multirow{2}{*}{418763,000} & \multirow{2}{*}{,009 } & Male & 921,06 \\
\hline & & & Female & 978,04 \\
\hline Measures for Reducing Cyberbullying among School Pupils. & Mann-Whitney U test & Asymp. Sig. (2-tailed) & Pupils' groups & Mean Rank \\
\hline Bring Together Pupils, Parents and All School Personnel to & \multirow{2}{*}{404812,500} & \multirow{2}{*}{,001 } & 10-14 age group & 977,83 \\
\hline Create Tools to Protect Pupils against Cyberbullying & & & $15-19$ age group & 907,05 \\
\hline
\end{tabular}


The gender differences are important to consider in the preventative work of cyberbullying. Girls, more likely than boys, use coping strategies if they were involved in cyberbullying and girls are more likely than boys to suggest that they would tell parents, teachers, as well as friends, if they were cyberbullied. This finding suggests that teachers need to adjust the preventive work according to gender, for example, encouraging boys to talk more about cyberbullying [8].

As it is shown in Table 7, girls are more active to consider preventative measures of cyberbullying among school pupils. Girls, more likely than boys, highlight the need of developing a positive school culture in which pupils would develop cordial relations with other pupils in school. Girls suggest to organize a multi-faceted creative teaching for pupils, in order to maximize the pupils' extracurricular activities. Girls, more often than boys, mentioned other preventive measures, such as: to provide anonymous phone-in line where pupils can report cyberbullying and to outline the consequences for pupils who are involved in cyberbullying. Girls, more likely than boys, are willing to give a priority for preventive measures of cyberbullying, which are related to learning environment. The strengthening of the pupil's self-esteem as a preventive measure of cyberbullying was mentioned more often by girls than by boys as well. It is evident that the girls are more active than boys in suggesting some measures for reducing cyberbullying among school pupils. Moreover, younger pupils are more positive toward bringing together pupils, parents and all school personnel to create tools to protect pupils against cyberbullying.

\section{Conclusions}

Cyberbullying is becoming a widespread phenomenon in pupils' lives and it is a form of aggression using electronic media, especially mobile phones and the Internet. The roots for cyberbullying among school pupils usually are hidden in the school environment and could be transferred to the virtual space. The results of the survey showed that pupils were more likely to experience cyberbullying via the mobile phone than the Internet. Every forth pupil had experienced or witnessed cyberbullying using the Internet and an even larger proportion had experienced or witnessed cyberbullying using the mobile phone.

Teachers' and pupils' perceptions of the cyberbullying frequency were quite different. In teachers' view it is a widespread phenomenon that occurs infrequently (1-3 times a month); while in pupils' view, it is not very wide-spread phenomenon, but is a serious problem because it happens repeatedly from once a week to daily exposure of cyberbullying.

The analysis of the scientific literature revealed that it is very important to create a holistic school policies addressing cyberbullying, which could be an inherent part of general anti-bullying policy in school [2], [15], [20]; to develop reactive prevention strategies of cyberbullying, such as delete, block or ignore messages, and to develop proactive prevention strategies of cyberbullying, such as rising the awareness, security and digital literacy among teachers and pupils in school [5], [8], [10], [14]. The issues of ethics in using the Internet could be incorporated within curriculum so as the pupils could be well educated on the usage of the Internet in proper ways [9], [23].

Cyberbullying can be reduced by improving culture and climate school [2], [5], [6], [15], [20], [22]. For example, to encourage pupils to participate in decision-making; to encourage pupils to report if cyberbullying occurs; and to increase trust and support among peers within the school setting. Some more specific intervention will be helpful, including how to contact mobile phone companies and the Internet service providers, and legal rights in these matters.

The prevention program of cyberbullying should focus on appropriate on-line behaviour. Teachers should tell pupils about the outcomes of inappropriate use of mobile telephones or the Internet, and help pupils to develop appropriate coping strategies of cyberbullying [14], [15]. Such approaches need to be implemented with gender and age differences in mind.

The teachers in the survey were more active than the pupils in suggesting various measures for preventing cyberbullying. The former thought that the most effective prevention measures would be: the development of pupils' positive self-esteem, the formation of a positive school culture and the involvement of the entire school community (pupils, their parents, and school staff). In the teachers' view, in order to minimize cyberbullying in school, the psychological factors must be consolidated. In addition, they thought that bringing together pupils, parents and all school personnel to create tools to protect pupils against cyberbullying should be taken into account. The findings highlight the importance of teachers in developing intervention and prevention plans against cyberbullying among school pupils. Appropriate teachers' actions to prevent cyberbullying and the significance of useful strategies in helping pupils must be taken into account. Teachers also need to provide better supervision when technology is used in school, classrooms. Teachers need to understand the significant implication of cyberbullying as well as to learn how to identify and handle such incidents.

From the perspective of the pupils, the most effective measures to prevent cyberbullying should be oriented toward psychological conditioning (to strengthen pupil's self-esteem and to outline the consequences for pupils who are involved in cyberbullying). It was underlined that an anonymous phone-in line would encourage pupils to talk more openly about the cyberbullying phenomenon.

It could be concluded, the strengthening of pupil's positive self-esteem is considered to be one of the most effective measures for reducing cyberbullying among school pupils in Lithuania (in contrast to other countries such as Great Britain and the United States). The pupils' answers 
corresponded more closely to the findings from other studies in the other countries than teachers'. For instance, the establishment of an anonymous phone-in line and the specification of consequences for pupils who are involved in cyberbullying are considered as significant preventative measures by pupils in Lithuania and other countries. In addition, differences in pupils' and teachers' views regarding preventative measures of cyberbullying lead to the following suggestions on cyberbullying prevention: firstly, to improve communication among teachers and pupils, secondly, to organize discussion tables in order to be able to understand pupils' needs better, and the last, to collaborate together in finding ways for implementation of suggested cyberbullying preventative measures and strategies in school.

\section{Acknowledgements}

The author gratefully acknowledges Barbara Joan Blair from Bergen University College and anonymous reviewers for valuable point of view on the article.

\section{REFERENCES}

[1] J. Balding. Young people in 2004: The health - related behaviour questionnaire results for 40,430 young people between the ages of 10 and 15. Exter, UK: Schools Health education Unit, 2004.

[2] K. Brown, M. Jackson, W. Cassidy, Cyber - Bullying: Developing Policy to Direct Responses That are Equitable and effective in Addressing This Special Form of Bullying, 2006. Canadian Journal of Educational Administration and Policy 57: http://umanitoba.ca/publications/cjeap/

[3] M.A. Campbell. Cyberbullying: An old problem in a new guise? Australian Journal of Guidance and Counseling, 15, 68-76, 2005.

[4] W. Cassidy, M. Jackson, K.N. Brown. Sticks and Stones Can Break My Bones, But How Can Pixels Hurt me? Experiences with Cyber - Bullying. School Psychology International 2009;30;383, 2009.

[5] T. Diamanduros, E. Downs, S.J. Jenkins. The Role of School Psychologists in the Assessment, Prevention, and Intervention of Cyberbullying. Psychology in the school, Vol. 45 (8), 2008.

[6] D.R. Dupper. School Bullying. New Perspectives on a Growing Problem. Oxford University Press, 2013.

[7] S. Eden, T. Heiman, D. Olenik-Shemesh. Teacher's perceptions, beliefs and concerns about cyberbullying. British Journal of Educational Technology Vol 44 No 6, 1036-1052, 2013.

[8] A. Frisen, S. Berne, L. Marin. Swedish pupils' suggested coping strategies if cyberbullied: Differences related to age and gender. Scandinavian Journal of Psychology, 2014, 55, 578-584, 2014.

[9] R.M. Kowalski, S.P. Limber. Electronic bullying among middle school students. Journal of Adolescent Health, 41, 22-30, 2007.

[10] R.M. Kowalski, S.P. Limber, P.W. Agatson. Cyberbullying. Bullying in the Digital Age. Blackwell Publishing, 2008.

[11] Q. Li. Cyberbullying in Schools: A Research of Gender Differences. School Psychology International 2006; 27; 157, 2006.

[12] M. Nelson. School Bullies Going High tech, 2003. Retrieved 14 July 2004 from

http://www.canoe.ca/NewsStand/LondonFreePress/News?20 03/09/02/174030.html

[13] A. Nocentini, J. Calmaestra, A. Schultze-Krumbholz, H. Scheithauer, R. Ortega, E. Menesini. Cyberbullying: Labels, Behaviours and Definition in Three European Countries. Australian Journal of Guidance and Counseling vol 20 No 2, 129-142, 2010.

[14] N. Noret, I. Rivers. The prevalence of bullying by text message or email: results of four year study. Poster presented at British Psychological Society Annual Conference, Cardiff, Scotland, 2006.

[15] J.W. Patchin, S. Hinduja. Bullies move beyond the schoolyard: A preliminary look at cyberbullying. Youth Violence and Juvenile Justice, 4(2), 148-169, 2006a.

[16] J.W. Patchin, S. Hinduja. Cyberbullying and self-esteem. Journal of School Health, 80, 614-621, $2006 \mathrm{~b}$.

[17] R. Pilkauskaitė - Valickienè, S. Raižiené, R. Žukauskienė. Elektroninių patyčių paplitimas tarp Klaipedos apskrities vyresniuju klasių moksleivių. Socialinis darbas 2009. No. 8(2), 114- 121, 2009.

[18] Raskauskas, J., Stoltz, A.D. (2007). Involvement in traditional and electronic bullying among adolescents. Development Psychology, 43(3), 564-575.

[19] A. Schultze-Krumbholz, H. Scheithauer. Social-Behavioral Correlates of Cyberbullying in a German Student Sample. Zeitschrift für Psychologie/ Journal of Psychology, Vol 217(4), 2009, 224-226, 2009.

[20] R. Slonje, P.K. Smith. Cyberbullying: Another main type of bullying? Scandinavian Journal of Psychology, 49, 147-154, 2008 .

[21] P.K. Smith. Bullying and Harassment in schools and the Rights of Children. Children and Society, vol. 14294-303, 2000.

[22] P.K. Smith, J. Mahdavi, K. Carvalho, S. Fisher, S. Russell, N. Tippett. Cyberbullying: it's nature and impact in secondary school pupils. Journal of Child Psychology and Psychiatry. Vol. 49(4), 2008.

[23] P.K. Smith, R. Slonje. Cyberbullying. Handbook of Bullying in schools. An international perspective (ed. Jimerson S.R., Swearer S.M., Espelage D.L.)Routledge. New York and London, 2010.

[24] B. Spears, P. Slee, L. Owens, B. Johnson. Behind the scenes and screens: Insights into the human dimension of covert and cyberbullying. Zeitschrift für Psychologie/ Journal of Psychology 217, 189-196, 2009.

[25] N. Willard. An Educator's Guide to Cyberbullying and Cyberthreats, 2004. Retrieved 6 October 2005 from 
http://cyberbully.org/docs/cbcteducator.pdf

[26] H. Vandebosch, K. Van Cleemput. Cyberbullying among youngsters: prevalence and profile of bullies and victims. New Media and Society, 11, 1-23, 2009.
[27] M.L. Yabarra, K.J. Mitchell. Online aggressor / targets, aggressors, and targets: a comparison of associated youth characteristics. Journal of Child Psychology and Psychiatry, 45, 1308-1316, 2004. 